\title{
Study Of Rationality Of Prescriptions \& Analysis Of Drugs Prescribed Among In-Patients Of Mcgann Teaching Hospital, S.I.M.S, Shimoga, Karnataka, India.
}

\author{
${ }^{1}$ Dr Nagaraja Prasad S, ${ }^{2}$ Dr Jagadeesh K, ${ }^{* 3}$ Dr Shreenivas Revankar \\ ${ }^{1,2,3}$ Department Of Pharmacology; Shimoga Institute Of Medical Sciences ,Shimoga Karnataka. \\ *Corresponding author:Dr Shreenivas P Revankar
}

\begin{abstract}
:
Objective: Irrational prescribing is a common problem in drug use. Rational prescribing can prevent \& avoid this. The present study was undertaken to evaluate the rationality of prescriptions according to WHO core drug use indicators.
\end{abstract}

Materials \& Methods: 1070 prescriptions from in-patient departments were randomly analysed for rational prescribing retrospectively for 5 months (from July to November 2013) based on WHO drug use indicators .

Results: Prescribing of brand name (54.11\%) was more common than generic name (45.89\%). An average of 5.3 drugs were prescribed per person. $6.63 \%$ of prescriptions were partially legible or no treatment was recorded in treatment chart.90.18\% of total drugs prescribed were from EDL \& 7.85\% of prescriptions had fixed dose combinations. Cephalosporins were the most commonly prescribed antibiotics. $3.36 \%$ of prescriptions have nil/incomplete diagnosis. Injectables were prescribed in $74.50 \%$ admissions.

Conclusions: Prescribing by generic name is to be promoted to avoid confusion in understanding prescriptions; this also adheres to WHO standards of rational prescribing. Also emphasis should be given to promote use of drugs from EDL \& to avoid incomplete/illegible prescriptions \& to properly diagnose all the cases treated at the hospital.

Keywords: Essential drug list (EDL), Fixed dose combinations (FDC), Irrational prescribing. WHO drug use indicator

\section{Introduction}

Prescription is a written order of a registered physician to the pharmacist with proper directions for the dispensing of prescribed drugs $\&$ their use by the patient ${ }^{[1]}$. Drug prescribing is an integral part in treatment of patients. Various drugs are prescribed for numerous diseases afflicting mankind. However it is often observed that the prescribers do not adhere to the process of right prescribing i.e. prescribing the right drug , to the right patient, at the right time, at right dose through the right route. These have been described as the $5 \mathrm{R}$ 's of right prescribing or 5R's of medication safety. A $6^{\text {th }} \mathrm{R}$ called right documentation is sometimes added to this. When one of these norms are violated medication errors are likely to occur ${ }^{[2,3]}$. Also rational prescribing involves "SANE criteria" i.e. safety, affordability, need \& efficacy of the drug ${ }^{[3]}$.

Good prescribing involves instruction on appropriate dose, preparation \& medication administration ${ }^{[4]}$. The prescribed medications should be periodically reviewed so that any errors in prescription are detected early $\&$ corrective measures be implemented to meet the standards ${ }^{[5]}$. Prescription based survey may be considered as one of the most cost effective methods to assess \& evaluate the prescribing attitude of clinicians \& dispensing practices of pharmacists ${ }^{[6]}$. Medication or drug use evaluation (DUE) study ${ }^{[7,8]}$ is one of the commonly used methods to survey the prescriptions. Drug use evaluation (DUE) is of three types: prospective, concurrent \& retrospective. Retrospective type of study is easy and accurate to perform as the information required is readily available. Therefore the pattern of drug use in hospital based setting needs to be monitored intermittently in order to analyze their rationality \& provide inputs to promote rational drug use.

The rational use of drugs requires that patients receive medications appropriate to their clinical needs, in doses that meet their own individual requirements, for an adequate period of time $\&$ at the lowest cost to them $\&$ their community ${ }^{[9]}$. According to National coordinating council for medication error reporting \& prevention (NCC-MERP) medication error is " any preventable event that may cause or lead to inappropriate medication use or patient harm while the medication is in the control of health care professional, patient or consumer" ${ }^{\text {"[10]. }}$ The rational use of drugs depends upon three perspectives namely patient, physician $\&$ healthcare provider perspective. The drug use indicators recommended by WHO cover all three perspectives ${ }^{[1]}$. These indicators may be used to study \& analyse the pattern of drug use in any hospital based setting. 


\section{Materials \& Methods:}

The study is retrospective, involving 1070 prescriptions among inpatients of Mc Gann teaching hospital Shimoga Institute of Medical sciences(S.I.M.S) during the periods of July to November 2013. The prescriptions were randomly chosen and analysed based on WHO drug use indicators ${ }^{[11]} \&$ other criteria for their:

1) Age \& sex statistics.

2) Average number of drugs prescribed per person.

3) Duration of treatment \& disease pattern like infectious, non-infectious, combined. System wise diagnosis \& incomplete or without any diagnosis.

4) Prescriptions that were completely legible, partially legible or no treatment recorded.

5) Prescriptions with an antibiotic \& type of antibiotic prescribed.

6) Drugs prescribed from EDL.

7) Prescriptions where drug was prescribed by brand name or generic name.

8) Number of fixed dose combinations prescribed.

9) $\%$ of Prescriptions with injections.

10) Prescriptions with vitamins \& tonics.

III. Results:

Table 1 : Age Statistics

\begin{tabular}{|c|c|c|}
\hline Age (yrs) & No. of patients & Percentage(\%) \\
\hline $0-10 \mathrm{yrs}$ & 104 & 9.72 \\
\hline $11-20 \mathrm{yrs}$ & 169 & 14.95 \\
\hline $21-30 \mathrm{yrs}$ & 342 & 31.96 \\
\hline $31-40 \mathrm{yrs}$ & 150 & 14.50 \\
\hline $41-50 \mathrm{yrs}$ & 106 & 9.91 \\
\hline $51-60 \mathrm{yrs}$ & 99 & 9.25 \\
\hline$>60 \mathrm{yrs}$ & 106 & 9.91 \\
\hline
\end{tabular}

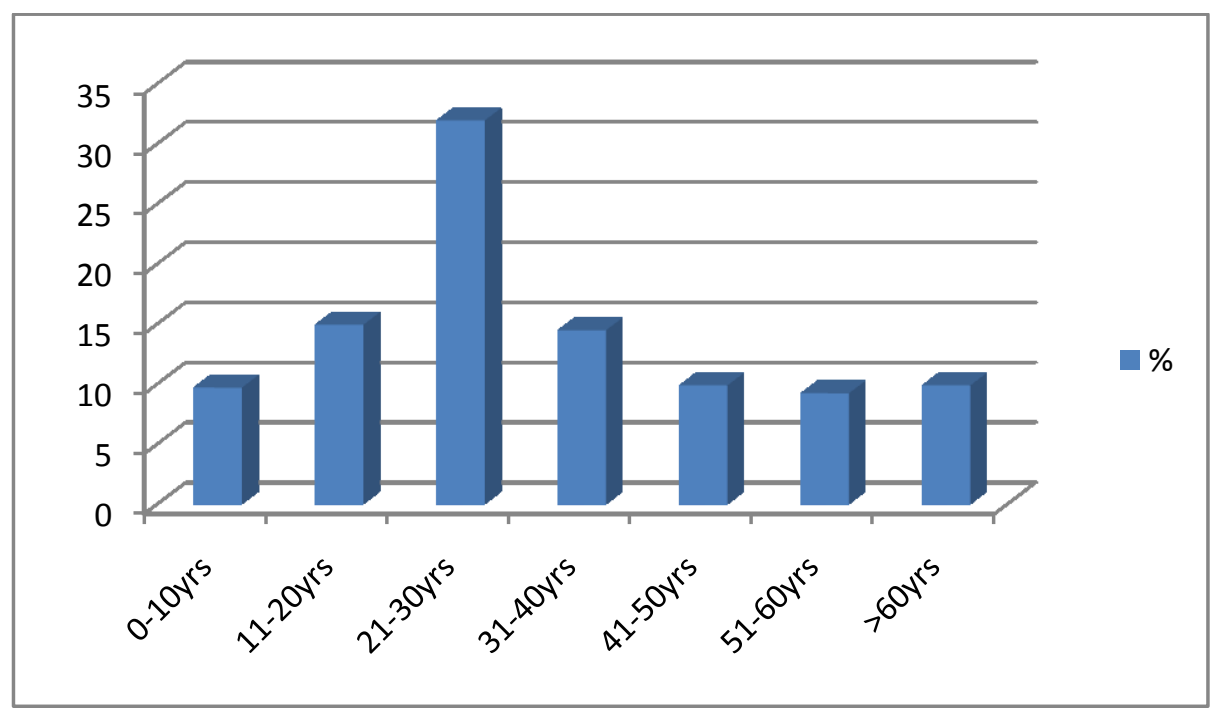

FIG 1: Age Distribution

Table 2:Duration Of Treatment Statistics:

\begin{tabular}{|c|c|c|}
\hline Duration of treatment (in days) & No of patients & Percentage(\%) \\
\hline$<1$ day & 100 & 9.35 \\
\hline $1-2$ days & 212 & 19.81 \\
\hline 3-5 days & 414 & 38.69 \\
\hline 6-10 days & 263 & 24.58 \\
\hline 11-15days & 035 & 03.27 \\
\hline$>15 d a y s$ & 018 & 01.68 \\
\hline Date of discharge not mentioned & 018 & 01.68 \\
\hline
\end{tabular}




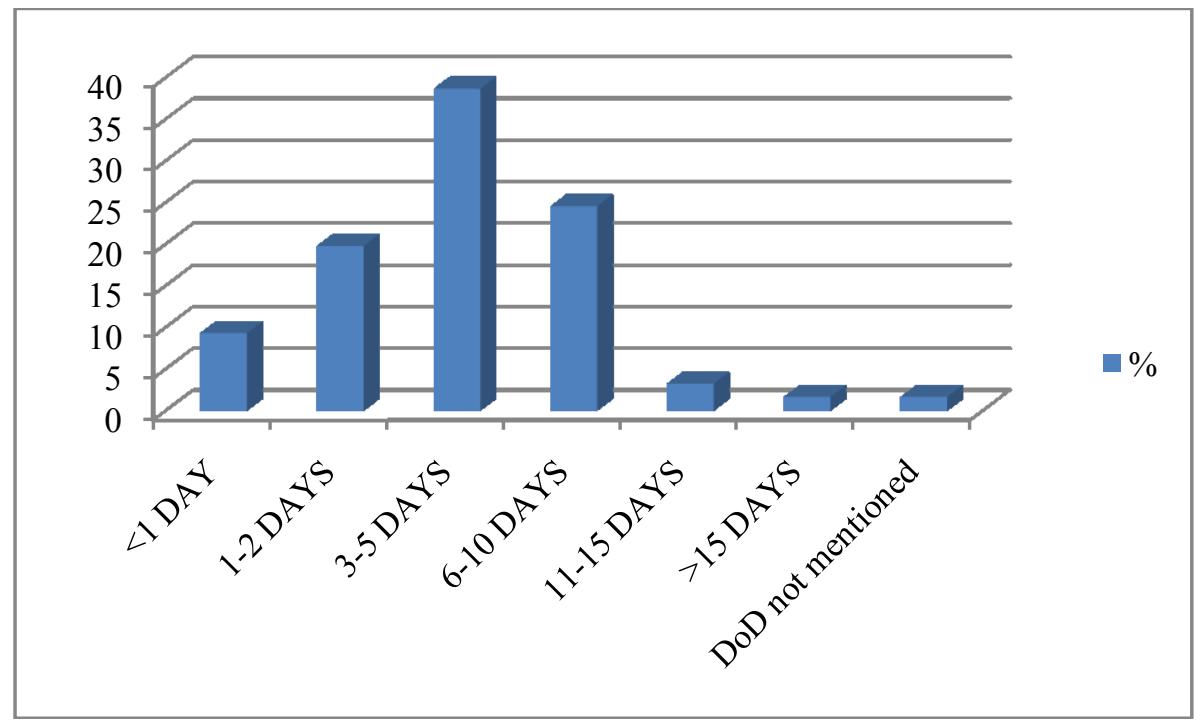

Fig 2: Duration Of Treatment

Regarding age group of patients admitted( table 1, fig 1) 0-10yrs (9.72\%), 11-20yrs(14.95\%),21$30 \mathrm{yrs}(31.96 \%), 31-40 \mathrm{yrs}(14.50 \%), 41-50 \mathrm{yrs} \quad(9.91 \%) \quad 51-60 \mathrm{yrs}(9.25 \%) \quad \&>60 \mathrm{yrs}(9.91 \%)$. Regarding sex of patients admitted males were $42.72 \%$ \& females were $57.28 \%$ respectively. A total of 5675 number of drugs were prescribed for 1070 prescriptions at 5.3 drugs per patient. $9.35 \%$ of patients were admitted for $<1$ day, $19.81 \%$ for $1-2$ days, $38.69 \%$ for $3-5$ days, $24.58 \%$ for $6-10$ days, $3.27 \%$ for $11-15$ days, $1.68 \%$ for $>15$ days ( table 2, fig 2) \& date of discharge was not mentioned in $1.68 \%$ of patients. Communicable diseases constituted $26.45 \%$ of cases while non-communicable diseases constituted $69.91 \%$ of cases, while $1.5 \%$ of cases were of both types. $6.63 \%$ of prescriptions were either illegible or partially legible or no treatment mentioned at all.

Table 3 : Percentage Of Antibiotics Prescribed Statistics:

\begin{tabular}{|c|c|c|}
\hline Antibiotics prescribed & Number(out of 1470) & Percentage(\%) \\
\hline sulfonamides & 3 & 0.20 \\
\hline Quinolones & 131 & 8.91 \\
\hline Penicillins & 122 & 4.30 \\
\hline Cephalosporins & 664.17 \\
\hline Aetracyclines \& chloramphenicol & 62 & 4.22 \\
\hline Aminoglycosides & 166 & 0.48 \\
\hline Macrolides & 7 & 3.61 \\
\hline Anti TB drugs & 53 & 0.27 \\
\hline Antifungals & 4 & 1.70 \\
\hline Nitroimidazoles & 25 & 14.29 \\
\hline Antihelmenthics & 210 & 1.09 \\
\hline Anticancer drugs & 16 & 0.48 \\
\hline
\end{tabular}

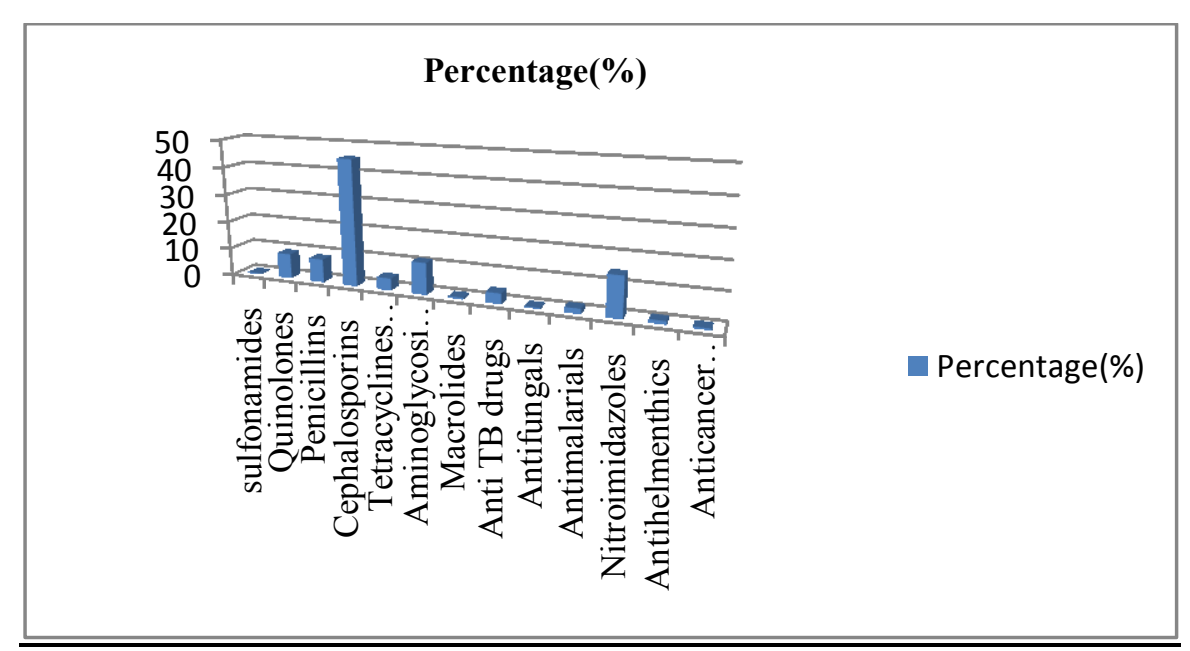

Fig 3: \% of Group of Antibiotic Prescribed 
Table 4: Antibiotic Prescription Pattern According To Age Group:

\begin{tabular}{|c|c|c|c|c|}
\hline \multirow[t]{2}{*}{ Drug group } & \multicolumn{3}{|c|}{ Age of patient( in years) } & \multirow[t]{2}{*}{ Total } \\
\hline & 0-18yrs & 19-60yrs & $>60 \mathrm{yrs}$ & \\
\hline Sulphonamides & 02 & 01 & 00 & 03 \\
\hline Quinolones & 21 & 93 & 17 & 131 \\
\hline Penicillins & 17 & 82 & 23 & 122 \\
\hline Cephalosporins & 147 & 470 & 47 & 664 \\
\hline Broad spectrum drugs & 11 & 49 & 02 & 62 \\
\hline Aminoglycosides & 95 & 67 & 04 & 166 \\
\hline Macrolides & 02 & 05 & 00 & 07 \\
\hline Anti TB drugs & 16 & 29 & 08 & 53 \\
\hline Antimalarials & 05 & 19 & 01 & 25 \\
\hline Nitroimidazoles & 21 & 178 & 11 & 210 \\
\hline Antihelmenthics & 02 & 14 & 00 & 16 \\
\hline Antifungal drugs & 00 & 04 & 00 & 04 \\
\hline Anticancer drugs & 00 & 03 & 04 & 07 \\
\hline
\end{tabular}

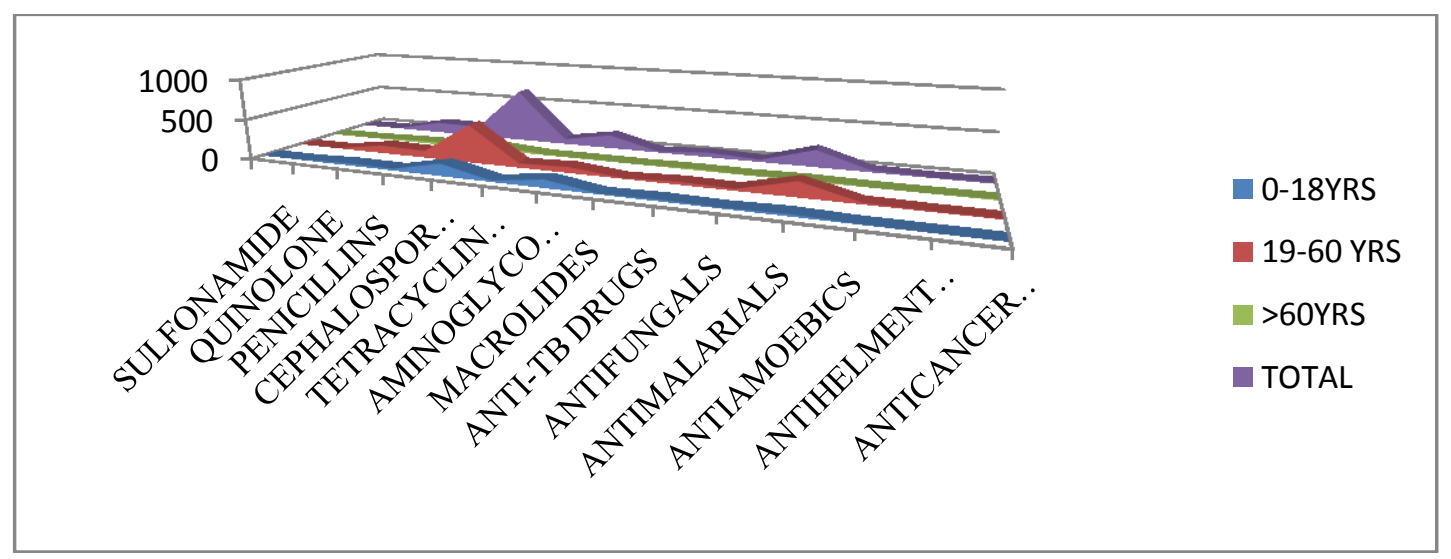

Fig 4: Age Wise Representation Of Number Of Antibiotics Prescribed

$25.92 \%$ of admissions an antibiotic was prescribed (table 3, fig 3) of which sulphonamides constituted $\quad 0.20 \%$,quinolones $8.91 \%$, penicillins $8.30 \%$,cephalosporins $\quad 45.17 \%$, tetracyclines \& chloramphenicol $4.22 \%$, aminoglycosides $11.29 \%$, macrolides $0.48 \%$, anti-tubercular drugs $3.61 \%$, antifungals $0.27 \%$, antimalarials $1.70 \%$, nitroimidazoles $14.29 \%$, antihelmenthics $1.09 \%$ \& anticancer drugs $0.48 \%$ of total antibiotics prescribed. Cephalosporins were most common antibiotics prescribed in all age groups(table 4, fig 4) while in $0-18 \mathrm{yr}$ age group $2^{\text {nd }}$ common were aminoglycosides \& in 19-60yr age group nitroimidazoles \& in $>60 \mathrm{yr}$ age group penicillins were $2^{\text {nd }}$ commonly prescribed drugs.

Table 5: Diagnosis Pattern Statistics:

\begin{tabular}{|c|c|c|}
\hline Disease diagnosis & Pumber of cases & Percentage(\%) \\
\hline R.S \& E.N.T & 86 & 14.04 \\
\hline G.I.T \& appendages & 151 & 29.63 \\
\hline OBG including neonatal diseases & 317 & 5.51 \\
\hline Musculoskeletal system & 59 & 4.95 \\
\hline CNS & 53 & 2.15 \\
\hline CVS & 23 & 0.75 \\
\hline Endocrines & 8 & 2.43 \\
\hline Dermatology & 26 & 2.80 \\
\hline Renals including prostrate & 30 & 1.40 \\
\hline Eye & 15 & 3.64 \\
\hline Blood \& lymphatics & 39 & 0.65 \\
\hline Multiple diagnosis & 07 & 9.53 \\
\hline Miscellaneous( including viral fever) & 102 & 11.05 \\
\hline No/Incomplete diagnosis & 118 & \\
\hline
\end{tabular}




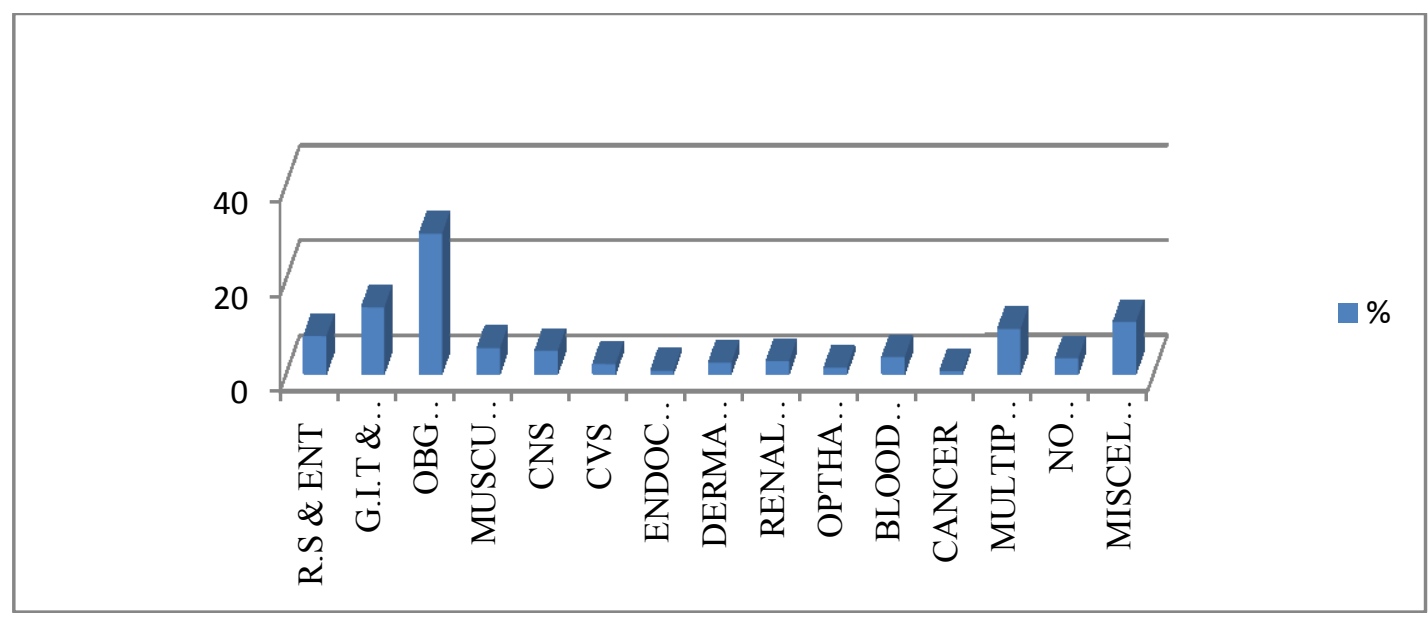

FIG 5: SYSTEM WISE DIAGNOSIS OF CASES IN \%

$90.18 \%$ of prescriptions contained drugs from EDL. In $54.11 \%$ of prescriptions brand name was used while $45.89 \%$ prescriptions contained generic name. Fixed dose combinations $9.85 \%$ of which cephalosporin plus sulbactam as injection was most common followed by anti-tubercular drug regimens. Injectables were prescribed in $74.50 \%$ of prescriptions. Vitamins \& tonics constituted $12.99 \%$ of drugs prescribed. Regarding diagnosis of cases (table 5, fig 5) respiratory $8.04 \%$, GIT \& its appendages $14.11 \%$, OBG including neonatal cases $29.63 \%$, musculoskeletal system cases $5.51 \%$, CNS diagnosis $4.95 \%$, CVS diagnosis $2.15 \%$, endocrines $0.75 \%$, dermatology $2.43 \%$, renal including prostate $2.80 \%$, eye $1.40 \%$, blood \& lymphatics $3.64 \%$, cancer related $0.65 \%$,multiple diagnosis $(2,3 \& 4) 9.53 \%$, incomplete/ nil diagnosis $3.36 \%$, miscellaneous (including viral fevers etc) $11.05 \%$.

\section{Discussion:}

Analysis of prescriptions based on above criteria reveals that age group of 21-30yrs (31.96\%)( table 1 \& fig 1) was maximum among patients admitted followed by $11-20$ years $(14.95 \%), 31-40$ years $(14.50 \%)$ \& 41-50years , $>60$ years $(9.91 \%$ each). This shows that $11-40$ years age group accounted for $62 \%$ of patients admitted in the hospital. It was found that females \& males constituted nearly $57.28 \% \& 42.72 \%$ respectively. A total of 5675 number of drugs were prescribed for 1700 prescriptions. An average of 5.3 drugs was prescribed per patient. This was much more than the reported statistics of 2-3 or 3-4 drugs prescribed per person ${ }^{[12,13]}$. However the difference noted in our study was because it was carried out among in- patients . Injectables were prescribed in $74.50 \%$ of admissions, even this can be explained based on the in-patient nature of our study. Regarding total duration of treatment 3-5 days treatment was noted to be the highest (38.69\%) followed by 610 days treatment(24.58\%), $1-2$ days treatment was found to be $(19.81 \%)$ and $<1$ day $(9.35 \%)$ (Table $2 \&$ fig 2).

$25.92 \%$ of drugs prescribed had an antibiotic in them, out of which cephalosporins (45.17\%) accounted for majority followed by nitroimidazoles $(14.29 \%)$ aminoglycosides $(11.29 \%) \&$ quinolones $(8.91 \%)$ ( table 3 \& fig 3). While cephalosporins accounted for maximum number of antibiotics prescribed among all the age groups the next most common antibiotic differed among various age groups (table 4,fig 4). Aminoglycosides in $0-18$ yr age group \& nitroimidazoles in the 19-60 year age group while in $>60$ year age group penicillins were $2^{\text {nd }}$ most common prescribed antibiotics in our study.

$54.11 \%$ of drugs were prescribed by their brand name \& $45.89 \%$ of drugs were prescribed by generic name. This can be avoided by educating the prescribers about the importance of prescribing drugs by generic name. Example in a tertiary care hospital it is easier to procure, distribute \& administer drugs when they are mentioned by their generic name except for drugs with narrow therapeutic index like lithium, phenytoin where prescribing by brand name is beneficial as it ensures proper bioavailability of drugs. 84 fixed dose combinations were prescribed in our study which accounted for $9.85 \%$ of drugs prescribed, majority of which were of cephalosporin plus sulbactam inj combination followed by anti-tubercular regimen combinations while ORS \& asthalin plus budecort combinations were third most commonly prescribed . $90.18 \%$ of drugs that were prescribed are from EDL which is in accordance with WHO principles of good prescribing practices. Still there is some scope (more number of drugs could be prescribed from EDL) for improvements in prescribing practices based on WHO essential drugs list. $12.99 \%$ of prescriptions had vitamins \& tonics, although in some cases it may be necessary to prescribe vitamins \& tonics like chronic intestinal diseases \& dietary deficiencies routine prescribing of vitamins $\&$ tonics should be discouraged. 
$6.63 \%$ of prescriptions were found to be completely or partially legible along with no treatment recorded for some patients, this could be because of the heavy patient load at the teaching hospital. However it should not be an excuse for not mentioning medications that are already administered to the patient.Regarding diagnosis $26.45 \%$ of diagnosis were of communicable diseases \& $69.91 \%$ were non-communicable diseases \& $1.5 \%$ was of both types. Multiple diagnoses $(2,3 \& 4)$ accounted for $9.53 \%$ of cases. Nil/incomplete diagnosis accounted for $3.36 \%$ of cases; therefore efforts should be made to diagnose all the cases as far as possible. When this is not possible at least a provisional diagnosis should be made \& entered in the appropriate column of inpatients admission chart. Regarding diagnosis pattern(table 5, fig 5), OBG cases including neonatal diagnosis were most common (29.63\%) followed by diseases of the GIT including its appendages $(14.11 \%)$ while miscellaneous diagnosis(viral fever etc) accounted for $11.05 \%$ of cases.

A 2002 WHO publication proposed 12 core policies to promote rational use of medicines ${ }^{[14]}$. These are:

1) Mandated multi-disciplinary body to coordinate medicine use policies.

2) Evidence based clinical guidelines.

3) Essential medicines list based on treatments of choice.

4) Drugs \& therapeutics committees in districts \& hospitals.

5) Problem based learning in pharmacotherapy in undergraduate curricula.

6) Continuing in-service medical education as a licensure requirement.

7) Supervision of health care workers, audit of prescriptions \& providing feedback to prescribers.

8) Provision of drug bulletin on medicines.

9) Public education about medicines.

10) Avoidance of perverse financial incentives.

11) Appropriate \& enforced regulations.

12) Sufficient government expenditure to ensure availability of medicines \& staff.

Implementation of these policies will help prevent to a great extent irrational prescribing \& promote rational drug therapy.

\section{Conclusion:}

Most of drugs prescribed were from $\operatorname{EDL}(90.18 \%)$, brand name prescribing is considerably more $(54.11 \%)$, nil/ incomplete diagnosis $(3.36 \%)$ \& no treatment mentioned in treatment chart $(6.63 \%)$ should be as minimal as possible. $25.92 \%$ of drugs prescribed were antibiotics of which cephalosporins were most commonly prescribed.5.3 number of drugs were prescribed per person. $7.85 \%$ of prescriptions had Fixed dose combinations of which cephalosporin plus sulbactam injection was most commonly prescribed. Therefore it is mandatory to educate about rational prescribing from early days of medical education \& provide updates \& scrutiny needed for clinicians. This will minimise \& prevent irrational prescriptions in the benefit of the patient \& society at large.

\section{References}

[1]. S.D. Seth, Vimlesh Seth. Textbook of pharmacology. $3^{\text {rd }}$ ed Elsevier, New Delhi 2009. p. XVI . 48.

[2]. Annie Collins Abrams, Sandra Smith Penninton, Carol Barnett Lammon. Clinical Drug therapy Rationales for nursing practice. 8th ed . Lippincott Williams \& Wilkins; 2007. p.31.

[3]. Sharma HL, Sharma KK. Principles of pharmacology $2^{\text {nd }}$ ed Paras medical publishers 2011.p.106.

[4]. John L.Reid, Peter .C.Rubin \& Matthew P Walters. Lecture notes Pharmacology \& therapeutics, $7^{\text {th }}$ ed Blackwell publishing ltd 2006.p.288.

[5]. Derek G Wallas, Andrew G.Renwick, Keith Hilier. Medical Pharmacology \& therapeutics. $3^{\text {rd }}$ ed Saunders Elsevier 2010. p.699.

[6]. Tiwari H, Kumar A \& Kulkarni S K. Prescription monitoring of antihypertensive drug utilisation at Panjab university health care centre in India. Singapore Med J 2004, 45 (3); 117-120.

[7]. Arthur J Atkinson,Jr., Darell R.Abernathy, Charles E.Daniels, Robert L .Dedrick \& Stanford P Markey. Principles of Clinical Pharmacology. $2^{\text {nd }}$ ed Academic Press, Elsevier Inc 2007.p.414-416.

[8]. MS Phillips, Gayman J E, Todd M W. ASHP Guidelines on medication use evaluation. American Society of health system pharmacists. Am J Health Syst Pharm. 1996; 53:1953-55.

[9]. World health organisation. The rational use of drugs. Report of the conference of experts. Nairobi, $25-29$ nov 1985 Geneva. World Health Organisation, 1987.

[10]. National coordinating council for medication error reporting \& prevention Rockville ,MD:US pharmacopoeia ; 1999(Internet http://www.nccmerp.org).

[11]. International network for rational use of drugs \& WHO. How to investigate drug use in health facilities: Selected drug use indicators. Geneva: World Health Organisation. 1993;1:1-87.

[12]. Mishra H, Mishra R, Mondal A. Prescription pattern of antimicrobial drugs in paediatric outpatient department of a tertiary care teaching hospital of North India. Int J Basic Clin Pharmacol 2014; 3: 385-8.

[13]. KD Tripathi. Essentials of medical pharmacology $7^{\text {th }}$ ed Jaypee Brothers Medical Publishers(P) Ltd 2013.p.72.

[14]. World Health Organisation. Promoting rational use of medicines: core components 2002. WHO Policy Perspectives on Medicines No. 5, Geneva, World Health Organization, 2002. 